\title{
A Peer Research Consultant Program: Feasibility and Outcomes
}

\author{
Francisca Beer, Christina M. Hassija, California State University, San Bernardino \\ Arturo Covarrubias-Paniagua, California State University, San Bernardino \\ Jeffrey M. Thompson, California State University, San Bernardino
}

\begin{abstract}
The authors discuss their study of the Peer Research Consultant (PRC) program at California State University, San Bernardino. During the 2016-2017 academic year, 13 courses, with 853 students enrolled, participated in the PRC program. Program participants completed preand post-measures assessing demographic information, perceptions of skill level, and perceived gains following program participation. Students who participated in the PRC program showed an increase in overall course grades $(M=3.11)$ compared to those who did not $(M=2.82$; $p<0.05)$. Similar findings were observed among underrepresented minority (URM) students who participated $(M=3.05)$ and those who did not $(M=2.73, p<0.05)$. Program participants reported high satisfaction with the program and improved confidence in skills.
\end{abstract}

Keywords: high-impact practices, peer research consultants, undergraduate research

doi: 10.18833/spur/2/3/4

Increasing efforts have been focused on engaging undergraduate students in high-impact practices (HIPs) that include activities such as research and creative pursuits, writing-intensive courses, collaborative assignments and projects, and service learning. Research suggests that a primary outcome of incorporating HIPs into existing curriculum is improved academic success, such as increased student retention and graduation rates (Kuh 2008). HIPs can take many forms, and varied modalities can be implemented simultaneously. One HIP emphasizes increasing research experiences for undergraduate students in all disciplines (Kuh 2008). The primary objective of such efforts is to enhance students' familiarity with empirical observation and ability to engage in systematic investigation and research (Kuh 2008). Research also has shown that engagement of undergraduate students in research can result in improved retention, graduation rates, academic performance, and academic satisfaction and higher enrollment in graduate programs (Gregerman 2009; Hathaway, Nagda, and Gregerman 2002; Nagda et al. 1998; Pukkila et al. 2013). Studies also have shown that students who participate in undergraduate research report greater selfconfidence, which can enhance their ability to work independently (Brownell and Swaner 2010; Lopatto 2010).

Further, research suggests that faculty members can have a large impact on student success, particularly if they are willing to interact with students outside of a classroom setting. For instance, studies have shown that students who work with a faculty member on a research project have improved learning outcomes when the faculty member clearly explains expectations and provides feedback during and after the project (National Survey of Student Engagement 2007). This is true for all students, not just those belonging to underrepresented minority (URM) or low-income groups. Accordingly, increasing opportunities for students to engage in research projects, while obtaining individual support, appears to be particularly valuable.

Numerous universities also have recognized that peer mentoring also leads to a better rate of retention and graduation for all students. Successful peer mentoring in higher education is the result of relationships among 
mentors, mentees, and faculty, and peer mentoring supports different learning styles. Lawson and Johnson (2002) have documented that higher education often ignores the learning styles of students who can be "thinkers," "feelers," "doers," or "observers." Peer mentoring is typically conducted between people of equal status and implies guiding, assisting, sponsoring, tutoring, and coaching. For the peer mentor, these activities lead to substantial benefits: personal growth, increased confidence, better self-esteem, opportunity to build a reputation, enhanced professional development, networking, and sharing of ideas (Ehrich, Hansford, and Tennent 2004). For faculty, peer mentoring provides a socially supportive environment that allows students to develop valuable skills and knowledge to integrate into their classes and their research (Thorsheim, Lacost, and Narum 2010). For mentees, peer mentoring promotes teamwork, critical inquiry and reflection, communication and comprehension skills, and development of self-management skills (Boud, Cohen, and Sampson 2014).

The Peer Research Consultant (PRC) program combines the benefits of peer mentoring with those of HIPs and undergraduate research. This research focuses on the PRC program benefits for students. Combining peer mentoring with undergraduate research will contribute to building a community of scholars that fosters innovation and a sense of purpose and achievement. In doing so, the PRC program is intended to bolster the university's mission of offering a challenging and innovative environment that increases the implementation of HIPs via intellectual interaction and creativity while contributing to the mission of increasing undergraduate retention and graduation rates.

\section{The Peer Research Consultant Program}

The Office of Student Research (OSR) was established at California State University, San Bernardino (CSUSB) to provide students with increased opportunities to participate in research and creative projects, with the aim of increasing student graduation and retention rates. The OSR created a PRC program modeled partly after the University of North Carolina at Chapel Hill's Graduate Research Consultant Program. The PRC program was initially designed and piloted during the 2012-2013 academic year. The mission of the PRC program is to contribute to building a community of scholars that fosters innovation and develops a sense of purpose and achievement. The PRC program utilizes peer mentors who support research activities conducted by undergraduate students as part of their required coursework for a specific class. The PRC program is designed to achieve the following goals: (1) greater gains in mastering both content and contextual knowledge; (2) enhanced ability to put classroom knowledge into practice; (3) increased creativity and critical thinking; (4) enhanced problem-solving skills; (5) enhanced communication skills, both oral and written; and (6) enhanced technical skills within the discipline.
Intended to support undergraduate courses that incorporate research and creative activities, the PRC program provides instructors with an undergraduate or graduate student who serves as a PRC and whose assistance helps turn course assignments into research projects. The PRC is chosen by the faculty member at the time of application to the program, and often is a current student engaged in independent research with the faculty member and/or a former student who excelled in the course that the faculty member is requesting become part of the PRC program. The faculty member cooperates with the PRC to create course assignments that encourage research and creative activities (e.g., a research project or literature review paper). PRCs fulfill a role that differs from that of a tutor or teaching assistant, as they do not teach or grade students' work. PRCs may attend some or all class sessions and contribute to course content via in-class presentations on course-related material or professional development, depending on the preferences and needs of the instructor. In addition, all PRCs offer support for undergraduate students for up to 10 hours per week outside of class time, during which they perform a variety of activities associated with research, such as conducting literature reviews, designing and executing research, analyzing data, and writing and disseminating results.

The OSR encourages every academic discipline at CSUSB to participate in the PRC program. One aim of the PRC program is to support the incorporation of research into the curriculum so that a greater number of students have access to research experiences, compared to the relatively small number of undergraduate students who are able to participate in extracurricular research projects. Undergraduate research and creative activities may include class-based activities (including quantitative writing assignments that engage students with an open-ended problem requiring them to understand principles and concepts rather than simply apply formulas), class-based projects (like servicelearning programs that involve students in organized community service that addresses local needs and develops academic skills), or capstone experiences (such as senior research projects or honors research experiences that allow students to develop and explore a research question of their own). Faculty members are encouraged to utilize whatever strategies and methods best fit the needs of their particular class. Furthermore, because of the variable intensity of undergraduate research and creative activities, the program offers faculty the flexibility to engage students broadly in all aspects of the research process or to have students engage in more in-depth investigation of a particular research question, depending on the desired course outcomes.

Since its inception in the 2012-2013 academic year, the demand for the PRC program has grown exponentially. Although the OSR has acquired a grant to support the PRC program, funding remains limited. At this stage, faculty 
members compete for funding from the OSR and must submit an application that outlines course objectives and describes the specific need for a PRC. All applications are reviewed by the OSR director for competitiveness and are then forwarded for review to the OSR Review Committee (ORC), a committee composed of faculty members from each college. The ORC is asked to make recommendations to the OSR director based on clarity of the proposal, assessment of the benefits of the PRC program, and the description of the research project and proposed research activities. Based on these recommendations, the OSR director selects the classes. Over the course of the program, the OSR director ensures compliance of PRCs with the goals of the program by conducting monthly meetings with all PRC student facilitators remaining in constant communication with faculty, and maintaining an open door policy for all participants.

Approved courses ideally contain strong research or creative activity components that facilitate faculty construction of research projects. PRCs, selected by faculty, are hired, trained, and paid by the OSR at the rate of $\$ 14.85$ per hour. The PRCs are required to participate in a two-day training hosted by the OSR and supported by other faculty and staff members on campus. This training provides PRCs with the necessary knowledge and skills to effectively serve in this position, and includes workshops on ethics, confidentiality, pedagogy, and conducting peer sessions, among other topics. On the first day of class, faculty and the PRC facilitator introduce students to the program. Students are informed of the program's features, the role of the PRC facilitator, and the benefits of PRC session participation. At the conclusion of this initial meeting, students take a pre-program survey to evaluate confidence in skills. At the end of the course term, students complete follow-up surveys, and faculty are asked to provide detailed information about the peer facilitator's performance.

This article describes the PRC program and outcomes of student participants versus nonparticipants. Specifically, effectiveness of the PRC program was evaluated by examining participants' satisfaction and course performance.

\section{Participants}

During the 2016-2017 academic year, 13 courses participated in the PRC program. Across all 13 participating courses, 853 students ( $n=516$ female; $n=335$ male; $n=$ 2 unknown) were enrolled. Roughly 47 percent $(n=404)$ of enrolled students participated in the PRC program ( $n=256$ female; $n=148$ male). With respect to URM students (those who identified as Hispanic/Latino, African American, and Native American), 560 were enrolled in participating classes, and 265 (47 percent) participated in the PRC program. Additional demographic information for program participants and nonparticipants is outlined in Table 1.

\section{Measures}

\section{Demographic Information}

Demographic information for program participants and nonparticipants was obtained from CSUSB's Office of Institutional Research (IR). Information included students' gender, ethnicity, class standing, Pell Grant eligibility, first-generation college student status, high school grade point average, and college entrance exam scores.

\section{Academic Skills}

A 14-item measure (see Table 2) was created to assess participants' confidence in a variety of academic skills and administered at the start and end of the program to participants. The measure asked respondents to rate themselves in a variety of academic areas on a five-point scale $(1=$ very low; $5=$ very high). Sample areas included subject knowledge, critical thinking skills, and problem-solving skills. Reliability for this measure was $\alpha=0.83(n=272)$ for participants' pre-program responses and $\alpha=0.91(n=$ 254) for post-program responses.

\section{Perceived Gains}

A measure consisting of 15 items (see Table 3) was created to assess participants' perceived gains following participation in the PRC program. Participants were asked to indicate their level of agreement to statements describing potential gains following participation in the PRC program on a five-point scale $(1=$ strongly disagree; $5=$ strongly agree). Sample items included "attending peer research consultant sessions strengthened my subject knowledge" and "attending peer research consultant sessions helped me master the course content." Reliability for the perceived gains measure was $\alpha=0.96$.

\section{Academic Performance}

Final course grades for PRC program participants and nonparticipants were obtained from the university's IR office. See Table 4.

\section{Procedure}

The PRC program was offered during the fall, winter, and spring quarters (each quarter is 10 weeks long) of the 2016-2017 academic year. Program participants and nonparticipants completed pre- and post-program measures during the first and last week of classes, assessing demographic information and self-perception of academic skill levels (e.g., knowledge of course content, critical thinking skills, problem-solving skills, written communication skills). Program participants completed a measure of perceived gains at the end of the program. Additionally, information on course grades was pulled for each participating course to determine differences between course grades for PRC participants and nonparticipants. Data collected were approved by the institutional review board at CSUSB for use in the present study. 
TABLE 1. Demographic Information: PRC Participants and Nonparticipants (2016-2017)

\begin{tabular}{|c|c|c|c|c|c|}
\hline & & \multicolumn{2}{|c|}{ Nonparticipants } & \multicolumn{2}{|c|}{ Participants } \\
\hline & & $n$ & $\%$ & $n$ & $\%$ \\
\hline Total & All Students & 449 & $100.0 \%$ & 404 & $100.0 \%$ \\
\hline \multirow[t]{2}{*}{ Gender } & Female & 260 & $57.9 \%$ & 256 & $63.4 \%$ \\
\hline & Male & 187 & $41.6 \%$ & 148 & $36.6 \%$ \\
\hline \multirow[t]{9}{*}{ Ethnicity } & African American & 26 & $5.8 \%$ & 14 & $3.5 \%$ \\
\hline & Asian & 31 & $6.9 \%$ & 35 & $8.7 \%$ \\
\hline & Hawaiian/Pacific Islander & 0 & $0.0 \%$ & 0 & $0.0 \%$ \\
\hline & Hispanic/Latino & 269 & $59.9 \%$ & 251 & $62.1 \%$ \\
\hline & Native American & 1 & $0.2 \%$ & 0 & $0.0 \%$ \\
\hline & Nonresident & 24 & $5.3 \%$ & 18 & $4.5 \%$ \\
\hline & Multiracial & 14 & $3.1 \%$ & 9 & $2.2 \%$ \\
\hline & Unknown & 25 & $5.6 \%$ & 14 & $3.5 \%$ \\
\hline & White & 59 & $13.1 \%$ & 63 & $15.6 \%$ \\
\hline \multirow[t]{5}{*}{ Class standing } & First-time, first-year students & 0 & $0.0 \%$ & 0 & $0.0 \%$ \\
\hline & First-year students & 1 & $0.2 \%$ & 1 & $0.2 \%$ \\
\hline & Second-year students & 15 & $3.3 \%$ & 19 & $4.7 \%$ \\
\hline & Third-year students & 236 & $52.6 \%$ & 99 & $24.5 \%$ \\
\hline & Fourth-year students & 195 & $43.4 \%$ & 285 & $70.5 \%$ \\
\hline \multirow[t]{2}{*}{ Pell eligible } & Yes & 269 & $59.9 \%$ & 257 & $63.6 \%$ \\
\hline & No/unknown & 180 & $40.1 \%$ & 147 & $36.4 \%$ \\
\hline \multirow[t]{2}{*}{ First generation } & Yes & 329 & $73.3 \%$ & 288 & $71.3 \%$ \\
\hline & Unknown & 120 & $26.7 \%$ & 116 & $28.7 \%$ \\
\hline \multirow[t]{5}{*}{ High school GPA } & Less than 2.50 & 9 & $2.0 \%$ & 7 & $1.7 \%$ \\
\hline & 2.50 to 2.99 & 61 & $13.6 \%$ & 52 & $12.9 \%$ \\
\hline & 3.00 to 3.49 & 164 & $36.5 \%$ & 139 & $34.4 \%$ \\
\hline & 3.50 and above & 66 & $14.7 \%$ & 68 & $16.8 \%$ \\
\hline & Unknown & 149 & $33.2 \%$ & 138 & $34.2 \%$ \\
\hline \multirow[t]{2}{*}{ Entrance exams } & ACT (average) & \multicolumn{2}{|c|}{18.33} & \multicolumn{2}{|c|}{19.14} \\
\hline & SAT (average) & \multicolumn{2}{|c|}{900.32} & \multicolumn{2}{|c|}{919.24} \\
\hline
\end{tabular}


A Peer Research Consultant Program

TABLE 2. Participants' Self-Reported Skill Confidence Pre- and Post-PRC Program (2016-2017)

\begin{tabular}{|c|c|c|c|c|}
\hline Confidence in academic skills & & Pre-PRC & Post-PRC & Sig. \\
\hline \multirow{3}{*}{ Subject knowledge } & $n$ & 297 & 147 & \multirow{3}{*}{$0.00^{\circ}$} \\
\hline & $M$ & 3.12 & 3.69 & \\
\hline & $S D$ & 0.74 & 0.87 & \\
\hline \multirow{3}{*}{ Understanding of the course content } & $n$ & 297 & 146 & \multirow{3}{*}{$0.00^{\mathrm{a}}$} \\
\hline & $M$ & 3.35 & 4.01 & \\
\hline & $S D$ & 0.70 & 0.78 & \\
\hline \multirow{3}{*}{ Creative skills } & $n$ & 296 & 147 & \multirow{3}{*}{0.04} \\
\hline & $M$ & 3.53 & 3.69 & \\
\hline & $S D$ & 0.90 & 0.91 & \\
\hline \multirow{3}{*}{ Critical thinking skills } & $n$ & 298 & 147 & \multirow{3}{*}{$0.01^{\mathrm{a}}$} \\
\hline & $M$ & 3.70 & 3.90 & \\
\hline & $S D$ & 0.73 & 0.83 & \\
\hline \multirow{3}{*}{ Problem-solving skills } & $n$ & 297 & 147 & \multirow{3}{*}{$0.00^{a}$} \\
\hline & $M$ & 3.73 & 3.98 & \\
\hline & $S D$ & 0.75 & 0.81 & \\
\hline \multirow{3}{*}{ Oral communication skills } & $n$ & 297 & 147 & \multirow{3}{*}{$0.00^{\circ}$} \\
\hline & $M$ & 3.46 & 3.76 & \\
\hline & $S D$ & 0.97 & 1.02 & \\
\hline \multirow{3}{*}{ Written communication skills } & $n$ & 298 & 147 & \multirow{3}{*}{$0.00^{\mathrm{a}}$} \\
\hline & $M$ & 3.59 & 3.88 & \\
\hline & $S D$ & 0.88 & 0.91 & \\
\hline \multirow{3}{*}{$\begin{array}{l}\text { Technical skills within the discipline: } \\
\text { Creating data collection instrument }\end{array}$} & $n$ & 291 & 146 & \multirow{3}{*}{$0.00^{2}$} \\
\hline & $M$ & 3.05 & 3.53 & \\
\hline & $S D$ & 0.82 & 0.93 & \\
\hline \multirow{3}{*}{$\begin{array}{l}\text { Technical skills within the discipline: } \\
\text { Data analysis }\end{array}$} & $n$ & 290 & 146 & \multirow{3}{*}{$0.00^{\mathrm{a}}$} \\
\hline & $M$ & 3.02 & 3.52 & \\
\hline & $S D$ & 0.84 & 0.93 & \\
\hline \multirow{3}{*}{$\begin{array}{l}\text { Technical skills within the discipline: } \\
\text { Statistics }\end{array}$} & $n$ & 290 & 145 & \multirow{3}{*}{$0.00^{\circ}$} \\
\hline & $M$ & 2.81 & 3.34 & \\
\hline & $S D$ & 0.86 & 0.87 & \\
\hline \multirow{3}{*}{$\begin{array}{l}\text { Technical skills within the discipline: } \\
\text { Research design }\end{array}$} & $n$ & 288 & 146 & \multirow{3}{*}{$0.00^{2}$} \\
\hline & $M$ & 2.86 & 3.42 & \\
\hline & $S D$ & 0.83 & 0.94 & \\
\hline \multirow{3}{*}{ Working collaboratively with other students } & $n$ & 293 & 146 & \multirow{3}{*}{0.31} \\
\hline & $M$ & 4.08 & 4.12 & \\
\hline & $S D$ & 0.81 & 0.83 & \\
\hline
\end{tabular}

(table continues)

$8 \quad$ Scholarship and Practice of Undergraduate Research 
TABLE 2. (cont.)

\begin{tabular}{|c|c|c|c|c|}
\hline \multirow{3}{*}{ Ability to learn independently } & $n$ & 289 & 146 & \multirow{3}{*}{0.40} \\
\hline & $M$ & 4.24 & 4.22 & \\
\hline & $S D$ & 0.69 & 0.85 & \\
\hline \multirow{3}{*}{ Ability to learn effectively } & $n$ & 292 & 146 & \multirow{3}{*}{0.33} \\
\hline & $M$ & 4.14 & 4.17 & \\
\hline & $S D$ & 0.70 & 0.84 & \\
\hline \multirow{3}{*}{ Total score } & $n$ & 124 & 124 & \multirow{3}{*}{$0.00^{2}$} \\
\hline & $M$ & 47.86 & 52.28 & \\
\hline & $S D$ & 6.05 & 7.02 & \\
\hline
\end{tabular}

Note: Post-program survey includes only those who attended at least one session. Sig $=$ significance, $n=$ sample size, $M=$ mean, $S D,=$ Standard Deviation ${ }^{\mathrm{a}} p<0.05$.

\section{Results}

Thirteen classes participated in the PRC program during the 2016-2017 academic year: four classes in fall 2016, four classes in winter 2017, and five classes in spring 2017. Participating courses came from the following disciplines: biology (3), psychology (2), human development (1), kinesiology (3), marketing (1), social science (2), and anthropology (1).

\section{PRC Participants versus Nonparticipants}

To compare course grades of program participants versus nonparticipants and evaluate the effectiveness of the PRC program, $t$-tests were conducted (see Table 4). Results revealed significant differences between the mean course grades of the PRC participants $(M=3.11)$ and non-PRC participants $(M=2.82, p<0.05)$, with PRC participants having significantly higher course grades. Similar findings were observed for URM PRC participants $(M=3.05)$ and URM non-PRC participants $(M=2.73, p<0.05)$. Additionally, $t$-tests were conducted to determine preexisting differences between participants and nonparticipants. This included evaluation of high school GPA and college entrance exam scores (see Table 1). Results revealed no significant differences $(p>0.05)$ between program participants and nonparticipants for high school GPAs $(M$ $=3.26$ and 3.20, respectively), SAT scores $(M=919.24$ and 900.32 , respectively), or ACT scores $(M=19.14$ and 18.33, respectively).

\section{Academic Skills}

A $t$-test was conducted to compare changes in PRC program participants' reported confidence in academic skills on pre- and post-program testing using a composite score computed by summing all items for participants who completed both pre- and post-program measures. Results revealed that PRC program participants had significantly higher confidence in academic skills $(M=47.86$ preprogram versus $M=52.28$ post-program, $n=124)$. Table 2 presents means for the individual items, which revealed significant improvement in skill confidence for all items except working collaboratively with other students, ability to learn independently, and ability to learn effectively. Improvements in skill confidence were observed on all items except the ability to learn independently.

\section{Perceived Gains}

Finally, to evaluate the degree to which PRC program participants perceived gains following their participation, means were tabulated for each item on the measure of perceived gains (see Table 3). Overall PRC program participants appeared to be very satisfied with the experience, as the mean total score for the perceived gain measure was $57.78(S D=11.11, n=132)$ out of a maximum possible score of 75 . Specifically, participants reported a mean of 4.0 or higher for the following items assessing perceived gains: strengthened my subject knowledge, helped me master the course content, enhanced my ability to work collaboratively with others in groups, increased my ability to learn effectively, and enhanced my ability to put classroom knowledge into practice in the real world.

\section{Discussion}

The PRC appears to be a promising addition to courses designed to incorporate research activities. The findings indicate that students who participated in the PRC program had higher course grades. Similar findings were observed for URM students who participated in the program. Additionally, PRC participants reported improved confidence in a variety of academic skills following completion of the program. High levels of perceived gains also were observed among participants, with significant 
TABLE 3. Perceived Gains from Program Participation: Participant Means (2016-2017)

\begin{tabular}{|c|c|c|c|}
\hline Item & $M$ & $n$ & $S D$ \\
\hline Strengthened my subject knowledge & 4.19 & 144 & 0.78 \\
\hline Helped me master the course content & 4.08 & 144 & 0.81 \\
\hline Increased my creativity skills & 3.83 & 144 & 0.91 \\
\hline Increased my critical thinking skills & 3.97 & 145 & 0.86 \\
\hline Enhanced my problem-solving skills & 3.85 & 144 & 0.91 \\
\hline Enhanced my oral communication skills & 3.78 & 144 & 0.92 \\
\hline Enhanced my written communication skills & 3.83 & 144 & 0.91 \\
\hline $\begin{array}{l}\text { Increased my data collection instrument } \\
\text { creation skills }\end{array}$ & 3.83 & 142 & 0.91 \\
\hline Increased my data analysis skills & 3.81 & 143 & 0.95 \\
\hline Increased my statistics skills & 3.68 & 137 & 0.95 \\
\hline Increased my understanding of research design & 3.95 & 143 & 0.89 \\
\hline $\begin{array}{l}\text { Enhanced my ability to work collaboratively with } \\
\text { others in groups }\end{array}$ & 4.04 & 146 & 0.86 \\
\hline Increased my ability to learn independently & 3.80 & 144 & 0.95 \\
\hline Increased my ability to learn effectively & 4.04 & 145 & 0.87 \\
\hline $\begin{array}{l}\text { Enhanced my ability to put classroom knowledge into } \\
\text { practice in the real world }\end{array}$ & 4.06 & 145 & 0.90 \\
\hline Total score & 57.78 & 132 & 11.11 \\
\hline
\end{tabular}

Note $:$ Sig = significance, $n=$ sample size, $M=$ mean, $S D,=$ Standard Deviation

TABLE 4. Course Grades: PRC Participants versus Nonparticipants (2016-2017)

\begin{tabular}{|l|c|c|c|c|c|}
\hline & & Overall & No PRC & PRC & Difference \\
\hline All students & $n$ & 853 & 449 & 404 & - \\
\hline & Course grade & 2.96 & 2.82 & 3.11 & $0.29^{\mathrm{a}}$ \\
\hline URM students & $n$ & 560 & 295 & 265 & - \\
\hline & Course grade & 2.88 & 2.73 & 3.05 & $0.32^{\mathrm{a}}$ \\
\hline
\end{tabular}

Note: Course grade reflects mean course GPA for all students, participants and nonparticipants. Final column indicates gains from no lab to lab for course grade. ${ }^{\mathrm{a}} p<0.05$.

$P$ values existing for all but three of the 14 self-reported confidence categories.

The PRC program is easily adaptable and would scale well to serve any type of institution. First, the program can be easily implemented and fit within existing structures and available resources; it does not require additional facilities. Even existing facilities are minimally used, consisting of only a small-size classroom either prior to or following the standard class time. Additionally, students have reported usage of chatrooms or remote meetings as feasible alternatives. Second, the program has quickly won campus support, with the number of applications increasing each year and faculty indicating

10 Scholarship and Practice of Undergraduate Research 
satisfaction with the program. Experience has shown that faculty investment is key to program implementation, and faculty support and involvement have increased every year. This level of support has stemmed from the program's built-in flexibility. It provides faculty with a platform for success under their chosen conditions, while the PRC program manages the administrative aspects such as hiring, training, and completing background checks. Third, the program is generally low-cost. Peer consultants are paid about $\$ 140$ a week for a total cost of $\$ 1,400$ over a 10-week academic quarter. There are no extra costs associated with classroom reservations due to collaborations with on-campus departments.

Findings from the present study are not without limitations. The present data were derived from program evaluation data to assess the feasibility, outcomes, and student satisfaction with the PRC program. As a result, the study was not controlled, making it impossible to rule out alternative explanations for the improvements observed among program participants. Program participants self-selected to participate in the PRC program, and it is difficult to rule out potential confounding factors and draw definitive conclusions regarding the efficacy of the PRC program. For instance, more third- and fourth-year students participated in the program, making it unclear if those students were better prepared for the course at the outset or had other characteristics that may have affected their course performance. There were found to be no significant differences between participants and nonparticipants on baseline characteristics such as high school GPA and college entrance exam scores, but it is nevertheless possible that factors other than program participation account for the course grade differences. Further, not all PRC program participants completed the post-program measures of confidence in academic skills and perceived gains. Hence, it is unclear whether there were differences on these variables between those program participants who completed the post-program measures and those who did not. Future researchers should consider methods to correct for issues related to the lack of randomization and self-selection. Additionally, data from participants who attended at least one session were included in the analyses, and the impact of degree of participation on program outcomes was not measured. It would be useful to assess the number of sessions students attended to evaluate whether increased program participation leads to incremental improvements in course outcomes, confidence in skills, and perceived gains.

Despite these limitations, this study contributes to the larger field of higher education and offers further support for the implementation of programs that incorporate peer mentoring and encourage engagement in research and creative activities. The benefits identified in this research are in line with learning outcomes of initiatives such as Liberal Education and America's Promise (Kuh 2008). Faculty members' enthusiasm for the PRC program is promising. The PRC program has the potential to increase the number of faculty and student-authored presentations and publications, which helps to increase institutional visibility in the academic and scientific communities (Petrella and Jung 2008). For an institution that is teaching intensive, this benefit is not negligible.

Future research should address additional goals of the PRC program, especially the relationship between the PRC program and participants' ability to master both content and contextual knowledge. Future researchers also should prepare surveys for PRC student facilitators to evaluate program contributions to understanding of the research and creative activities process, career goals, communication skills, preparation for graduate school, opportunity to reflect on learning, interpersonal skills, and understanding of the research subject (Nora and Crisp 2007). Evaluation of faculty members participating in the program also should be considered. It is hoped that the CSUSB PRC program will contribute to the mission of the university by establishing a wider knowledge base and enhance all participants' understanding of their disciplines, problem-solving competencies, critical thinking, and ability to handle ambiguity. Ultimately, the PRC program teaches students to utilize knowledge and skills to benefit other students. It is expected that peer facilitators and participants will achieve enriched personal efficacy and improved interpersonal skills, embark on successful career development, and pursue commitments to helping others. There are future plans for wider dissemination of the program's outcomes to the larger campus during the annual student research symposium and a special session devoted to disseminating the research and creative activities produced via the PRC program.

\section{References}

Boud, David, Ruth Cohen, and Jane Sampson. 2014. Peer Learning in Higher Education: Learning from and with Each Other. London: Routledge. doi: 10.4324/9781315042565

Brownell, Jayne E., and Lynn E. Swaner. 2010. Five HighImpact Practices: Research on Learning Outcomes, Completion and Quality. Washington, DC: Association of American Colleges and Universities.

Ehrich, Lisa C., Brian Hansford, and Lee Tennent. 2004. "Formal Mentoring Programs in Education and Other Professions: A Review of the Literature." Educational Administration Quarterly 40: 518-540. doi: 10.1177/0013161x04267118

Gregerman, Sandra R. 2009. "Filling the Gap: The Role of Undergraduate Research in Student Retention and Academic Success." In Broadening Participation in Undergraduate Research: Fostering Excellence and Enhancing the Impact, ed. Mary K. Boyd and Jodi L. Wesemann, 245-256. Washington, DC: Council on Undergraduate Research. 
Hathaway, Russell S., Biren A. Nagda, and Sandra R. Gregerman. 2002. "The Relationship of Undergraduate Research Participation to Graduate and Professional Education Pursuit: An Empirical Study." Journal of College Student Development 43: 614-631.

Kuh, George D. 2008. High-Impact Educational Practices: What They Are, Who Has Access to Them, and Why They Matter. Washington, DC: Association of American Colleges and Universities.

Lawson, Anton. E., and Margaret Johnson. 2002. "The Validity of Kolb Learning Styles and Neo-Piagetian Developmental Levels in College Biology." Studies in Higher Education 7: 79-90. doi: 10.1080/03075070120099386

Lopatto, David. 2010. "Undergraduate Research as a HighImpact Student Experience.” Peer Review 12(2): 27.

Nagda, Biren A., Sandra R. Gregerman, John Jonides, William von Hippel, and Jennifer S. Lerner. 1998. "Undergraduate Student-Faculty Research Partnerships Affect Student Retention." Review of Higher Education 22: 55-72. doi: 10.1353/ rhe. 1998.0016

National Survey of Student Engagement. 2007. Experiences That Matter: Enhancing Student Learning and Success. Bloomington: Indiana University Center for Postsecondary Research.

Nora, Amaury, and Gloria Crisp. 2007. "Mentoring Students: Conceptualizing and Validating the Multi-Dimensions of a Support System." Journal of College Student Retention: Research, Theory \& Practice 9: 337-356. doi: 10.2190/cs.9.3.e

Petrella, John K., and Alan P. Jung. 2008. "Undergraduate Research: Importance, Benefits, and Challenges." International Journal of Exercise Science 1: 91-95.

Pukkila, Patricia J., Martha S. Arnold, Aijun Anna Li, and Donna M. Bickford. 2013. "The Graduate Research Consultant Program: Embedding Undergraduate Research across the Curriculum." CUR Quarterly 33(4): 28-33.

Thorsheim, Howard, Heather Lacost, and Jeanne L. Narum. 2010. "Peer Mentoring of Undergraduate Research in Community Colleges: A 'Transplantable' Model for Workshops." CUR Quarterly 31(2): 26-32.

\section{Christina M. Hassija}

California State University, San Bernardino, chassija@csusb.edu

Francisca Beer is a professor of finance, the director of the Office of Academic Equity, and an associate dean in the Jack H. Brown College at California State University, San Bernardino (CSUSB). She was the first CSUSB director of the Office of Student Research. She has published more than 50 articles in books, monographs, and refereed journals and was the co-principal investigator for $\$ 5$ million in grants.

Christina M. Hassija is the director of the Office of Student Research and an associate professor in the Department of Psychology at CSUSB. She completed her graduate training in clinical psychology at the University of Wyoming and her postdoctoral training at the National Center for Posttraumatic Stress Disorder through the Veterans Affairs Palo Alto Health Care System and Stanford University School of Medicine. She has authored more than 25 articles in books and refereed journals.

Arturo Covarrubias-Paniagua is a student in the master's program of industrial/organizational psychology at CSUSB. He has worked with the Office of Student Research as a graduate student assistant.

Jeffrey M. Thompson has been a faculty member and administrator at CSUSB for 30 years. In 1988, he joined the Department of Biology and was the director of the Electron Microscope and Image Analysis Center for 15 years. He served as the campus pre-professional adviser for 12 years and the chair of the Biology Department from 1998 to 2005. In 2004, he was appointed as the first associate provost for research and was assigned additional duties of dean of graduate studies in 2012. Thompson founded the Office of Student Research in 2014. He has 25 publications (nine with student coauthors) and more than $\$ 7$ million in grant awards. 